\title{
Environmental Science: Atmospheres at one year
}

\author{
Cite this: Environ. Sci.: Atmos., 2022, 2, Neil M. Donahue (iD * \\ 7
}

DOI: 10.1039/d2ea90001g

rsc.li/esatmospheres

\section{Introduction}

Happy Birthday to Environmental Science: Atmospheres! Over the past year our journal has gone from crawling to walking as a member of the Royal Society of Chemistry Environmental Science journal family. We joined Environmental Science: Processes \& Impacts, Environmental Science: Water Research \& Technology, and Environmental Science: Nano. We also look forward to welcoming our new sibling, Environmental Science: Advances, into the family.

Our aspiration is for each of our articles to change the way you think about Earth's atmosphere, or indeed planetary atmospheres in general. For our articles to change the way you think, they must be well written, they must present new science, and you need to read them. In our first volume we published 39 articles that were downloaded over 8000 times during 2021. To bring exposure to our authors we also held Desktop Seminar webcasts in April 2021, which we shall repeat in 2022. We are indexed in the Directory of Open Access Journals (DOAJ) and have been accepted for indexing in Scopus. As this implies, our journal is gold open access, and so all of our articles are free for scholars around the world.

Carnegie Mellon University Department of Chemistry, Pittsburgh, PA, USA. E-mail: nmd@andrew.cmu.edu; Tel: +1412 268-4415
The core subject of the journal is the atmosphere, but "environmental" emphasizes the connections between the atmosphere and other biogeochemical reservoirs, including the ocean, the biosphere, and the land surface. Emissions from the biosphere, including humans, and exposure of the biosphere and humans to gases and aerosols changed and transported by the atmosphere are all in our scope. The atmosphere also does not stop at the door or window, and indoor air is also well within our scope.

\section{Our team}

The journal is supported by a tremendous team of Associate Editors - TzungMay Fu, Stephen Klippenstein, Claudia Mohr, Nønne Prisle, and Lin Wang along with Editorial Board members Dwayne Heard and Joel Thornton - who collectively have guided us on our first steps and done the hard work of guiding manuscripts through the editorial process, along with the outstanding editorial staff of the Royal Society of Chemistry. Our goal is for smooth but rigorous editing and curation, with a first decision just about within one month from the time of submission. Nearly two thirds of our authors have opted for transparent peer review, which provides a permanent and public record of the review process.

\section{Themed issues and topics}

We have several mechanisms to draw attention to our papers. One is an Emerging Investigator themed collection. We have published two articles thus far, and we anticipate a steady stream in the coming years. Emerging investigator series: the red sky: investigating the hurricane Ophelia Saharan dust and biomass burning aerosol event (DOI: 10.1039/D1EA00052G) describes an unusual blend of Saharan dust and Iberian woodsmoke carried to England by the fading Hurricane Ophelia. Emerging Investigator Series: COVID-19 lockdown effects on aerosol particle size distributions in northern Italy (DOI: 10.1039/ D1EA00016K) describes the surprising consequences of the COVID lockdown in the Po Valley, where dramatic traffic reductions altered gas-phase chemistry and new-particle formation frequency but left the overall fine-particle pollution levels $\left(\mathrm{PM}_{2.5}\right.$ and $\left.\mathrm{PM}_{10}\right)$ largely unchanged. A companion article Modeling the effect of reduced traffic due to COVID-19 measures on air quality using a chemical transport model: impacts on the Po Valley and the Swiss Plateau regions (DOI: 10.1039/ D1EA00036E) - has the highest Altmetric Attention score among our 2021 articles. 
A Perspective Review with a high Altmetric Attention score is Optimising air quality co-benefits in a hydrogen economy: a case for hydrogen-specific standards for $\mathrm{NO}_{x}$ emissions (DOI: 10.1039/D1EA00037C), emphasizing the connection between sound atmospheric chemistry and public policy addressing low-carbon energy solutions. In addition to Perspective Reviews, we encourage Critical Reviews and have so far published one - Aging of atmospheric aerosols and the role of iron in catalyzing brown carbon formation (DOI: 10.1039/ D1EA00038A).

As the Editorial Board identifies areas of special scientific or societal interest, we organize Themed Issues curated by guest editors. Current Themed Issues (in addition to the Emerging Investigator series and a cross-journal Coronavirus issue) are "Aerosol formation in the urban atmosphere," "Brilliant light sources," and "Applications of unmanned aerial systems in atmospheric science." In the near future we expect to announce issues addressing bioaerosols and pathogen transmission inside droplets, chemical processes in global atmospheric models, dense networks of lowcost sensors, and levitated particles in atmospheric science.

\section{Conclusion}

The atmosphere covers the globe, and we aspire for our journal to not just be accessible to scholars worldwide but to welcome and be enriched by scholarship from around the world. We have already published a wide range of articles describing research on multiphase atmospheric chemistry and associated sources, deposition, consequences, and even policy implications. It was a challenging year in which to be born, with a far more virtual rollout than we would have liked, but I look forward to meeting you in person at various meetings around the world in the coming years, and to welcoming your outstanding research for publication in our journal as we toddle off to the next stage of our growth.

\section{Conflicts of interest}

The authors declare no conflicts. 